\title{
Stability analysis of roadway embankments supported by stone columns with the presence of water table under short-term and long-term conditions
}

\author{
Shaymaa Tareq Kadhim ${ }^{1, *}$, Ziad Bashar Fouad ${ }^{1}$ \\ ${ }^{1}$ Building and Construction Engineering Department, University of Technology, Baghdad, Iraq
}

\begin{abstract}
Use of stone column technique to improve soft foundation soils under roadway embankments has proven to increase the bearing capacity and reduce the potential settlement. The potential contribution of stone columns to the stability of roadway embankments against general (i.e. deep-seated) failure needs to be thoroughly investigated. Therefore, a two-dimensional finite difference model implemented by FLAC/SLOPE 7.0 software, was employed in this study to assess the stability of a roadway embankment fill built on a soft soil deposit improved by stone column technique. The stability factor of safety was obtained numerically under both short-term and long-term conditions with the presence of water table. Two methods were adopted to convert the three-dimensional model into plane strain condition: column wall and equivalent improved ground methods. The effect of various parameters was studied to evaluate their influence on the factor of safety against embankment instability. For instance, the column diameter, columns' spacing, soft soil properties for shortterm and long-term conditions, and the height and friction angle of the embankment fill. The results of this study are developed in several design charts.
\end{abstract}

\section{Introduction}

The most common type of slope instability that is more likely to happen when constructing roadway embankments on soft soil deposits is the global or deep-seated failure. Various ground improvement techniques were proposed to avoid this catastrophic failure; for instance: deeply mixed columns, stone columns, and sand compaction columns [1], [14]. Stone column technique has proven its effectiveness to overcome the embankment instability problem when constructed over a soft soil foundation. Stone columns possess the ability to improve the bearing capacity, minimize settlement, and enhance stability and drainage of improved ground [2], [5], [8], [11], [12], [14].

Embankments built on soft clay soils can fail due to slope instability in local, surficial, toe slope, and deepseated failure [6], as shown in Figure 1. However, the modes of failure of stone column-supported embankments are more complex since columns can fail in different modes of failure like: rotation, bending, shearing, and sliding [8]. Slope stability analysis can be performed using Limit Equilibrium Method (LEM), Finite Difference Method (FDM), and Finite Element Method (FEM) [4], [7]. Finite Difference Method offers several advantages over Limit Equilibrium Method in computing the factors of safety of slopes like: no assumption should be made for inter-slice forces, the possibility to have different failure surfaces with different shapes and the inclusion of structural elements to simulate different materials rather than assuming equivalent forces [9]. In addition, it was hypothesized that the factor of safety of slope stability computed from Finite Difference Method was 20\% lower than that resulted from Limit Equilibrium Method [3]. Reference [6] concluded that the Limit Equilibrium Method overestimates the stability factor of safety of deepmixed column-supported embankments when compared to Finite Difference Method due to the failure of columns in rotation, tension, or bending.

Reference [1] investigated the stability of embankments supported by granular columns in the undrained (i.e. shortterm) condition by means of two methods of equivalency; column wall and equivalent improved ground methods. They recommended a reduction factor of 0.9 for the factor of safety obtained from the equivalent improved ground method if a water table is not considered and 0.92 if the water table is taken into consideration.

In this paper, finite difference numerical analysis was adopted to assess the stability of stone column-supported embankment using FLAC/SLOPE 7.0 software, released

\footnotetext{
Corresponding author: shaimakadhim $@$ gmail.com
} 
by ITASCA Consulting Group. This paper aims to evaluate the stability of stone column-supported embankments in both short-term and long-term conditions with taking into consideration the influence of water table.

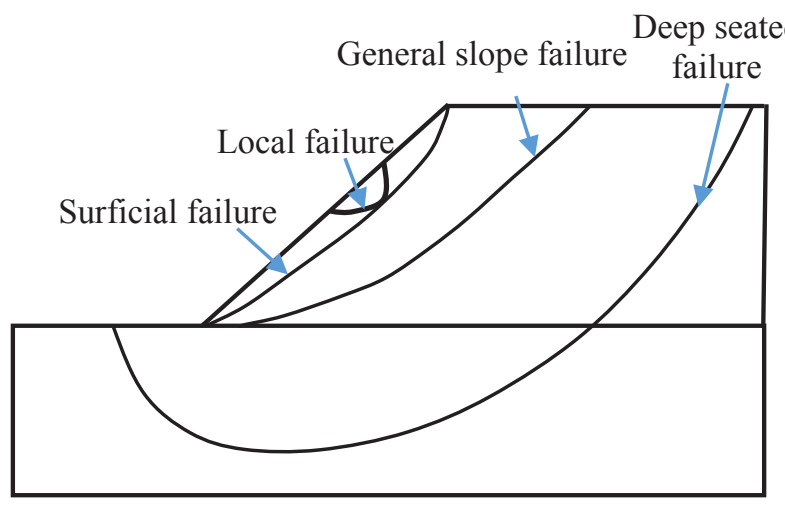

Fig. 1. Typical slope stability modes of failure for embankments constructed over soft soils [6].

\section{Two-dimensional numerical methods}

Due to the complexity of three-dimensional (3D) model of embankments, two methods were used to convert that model into plain strain condition (2D), which are: column wall method and equivalent improved ground method.

\subsection{Column wall method}

Reference [13] proposed this method by making an assumption that the width of the column wall is the same as the column diameter as illustrated in Figure 2.

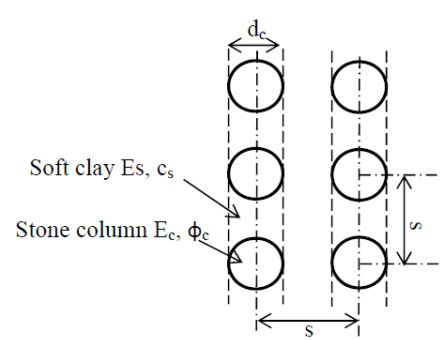

(a)

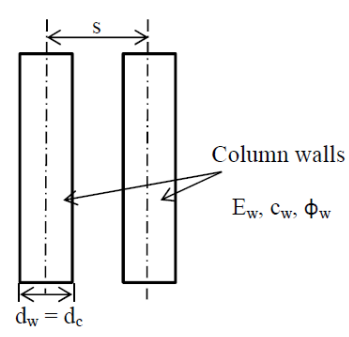

(b)
Fig. 2. The configuration of stone columns installed in soft clay soil: (a) Individual columns; and (b) Column walls [10].

The shear strength properties of the column wall can be determined as follows [14]:

$$
\begin{aligned}
& \mathrm{c}_{\mathrm{w}}=\mathrm{c}_{\mathrm{s}}\left(1-\mathrm{a}_{\mathrm{r}}\right) \\
& \phi_{\mathrm{w}}=\arctan \left(\mathrm{a}_{\mathrm{r}} \tan \phi_{\mathrm{c}}+\left(1-\mathrm{a}_{\mathrm{r}}\right) \tan \phi_{\mathrm{s}}\right) \\
& a_{r}=\frac{A_{c}}{d * s}
\end{aligned}
$$

in which $c_{\mathrm{w}}$ and $\mathrm{c}_{\mathrm{s}}=$ the cohesion of column wall and surrounding soil deposit, respectively; $\mathrm{a}_{\mathrm{r}}=$ the area replacement ratio with respect to the column wall; $\phi_{\mathrm{w}}, \phi_{\mathrm{s}}$ and $\phi_{\mathrm{c}}=$ the angle of internal friction of the column wall, soft soil and individual stone column, respectively; $\mathrm{Ac}=$ cross-sectional area of individual stone column; $d=$ stone column diameter; $\mathrm{s}=$ center to center spacing between columns.

\subsection{Equivalent Improved ground method}

The assumption of this method is based on that both the granular columns and the surrounding soft soil form a composite foundation. The equivalent shear strength parameters of the improved composite foundation are calculated by the following equations [1]:

$$
\begin{aligned}
& \mathrm{c}_{\mathrm{eq}}=\mathrm{c}_{\mathrm{s}}\left(1-\mathrm{a}_{\mathrm{s}}\right) \\
& \phi_{\mathrm{eq}}=\arctan \left(\mathrm{a}_{\mathrm{s}} \tan \phi_{\mathrm{c}}+\left(1-\mathrm{a}_{\mathrm{s}}\right) \tan \phi_{\mathrm{s}}\right) \\
& a_{\mathrm{s}}=\frac{\pi}{4}\left(\frac{d}{s}\right)^{2}
\end{aligned}
$$

in which $\mathrm{c}_{\mathrm{eq}}$ and $\mathrm{c}_{\mathrm{s}}=$ the cohesion of equivalent improved ground and soft soil deposit, respectively; $\phi_{\mathrm{eq}}, \phi_{\mathrm{s}}$ and $\phi_{\mathrm{c}}=$ the angle of internal friction of equivalent ground, soft soil and individual stone column, respectively; $\mathrm{a}_{\mathrm{s}}=$ the area replacement ratio of composite foundation. The granular columns were assumed to be installed in a square pattern in this research.

\section{Two-dimensional numerical modeling}

The parameters and dimensions of the stone columnsupported embankment for this study were selected from [1] excluding column diameter and center to center spacing. Figure 3 demonstrates the model geometry and mesh for column wall and equivalent improved ground methods. Half of the embankment geometry was adopted in this study utilizing FLAC/Slope 7.0 because of the model symmetry. The composite ground comprised of a soft clay layer of a $10 \mathrm{~m}$ thickness placed on top of a $2 \mathrm{~m}$ sand layer. The column diameter and length were chosen to be $0.5 \mathrm{~m}$ and $10 \mathrm{~m}$, respectively, according to the typical stone column size and length used in practice. The diameter to spacing ratio was assumed to be $20 \%$ as spacing measured from center to center of two adjacent columns was equal to $2.5 \mathrm{~m}$. The embankment dimensions were selected with a $5 \mathrm{~m}$ height, a crest width of $10 \mathrm{~m}$ and a slope equal to $2 \mathrm{H}: 1 \mathrm{~V}$. To prevent surficial failure, an exclude area function incorporated in FLAC/Slope 7.0 was activated to ensure that the failure surface did not penetrate a zone thickness of about $0.5 \mathrm{~m}$ located at the slope surface. The bottom boundary was restricted in both horizontal and vertical directions since the sand layer was placed above a firm layer of a bedrock. Furthermore, the boundaries on the two sides of the model were fixed in the horizontal direction and permitted to move freely in the vertical direction. 


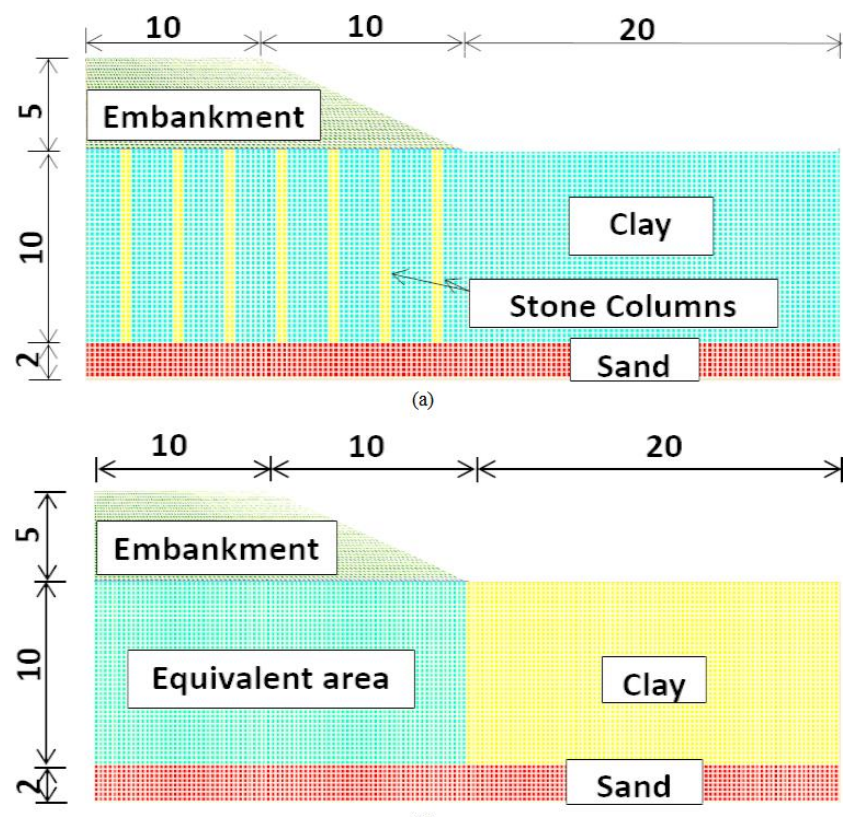

(b)

Fig. 3. FLAC models (unit: m): (a) Column wall; and (b) Equivalent improved ground.

The soft foundation soil, stone columns, and embankment fill were modeled as linearly elastic perfectly plastic materials with the Mohr-Coulomb failure criteria. Table 1 demonstrates the material properties of embankment fill, foundation soil, and stone columns in short-term condition (i.e. undrained condition), while Table 2 depicts the material properties in long-term condition (i.e. drained condition).

\section{Results and discussion}

The stability of embankments constructed on stone column-improved ground was explored in short-term and long-term conditions in the presence of water table via two methods of equivalency: column wall and equivalent improved ground. Various parameters were investigated in this research as follows:

\subsection{Diameter of stone column}

Figure 4 shows the effect of column diameter on embankment stability in short-term and long-term conditions. Three diameters were chosen for this study: $0.25 \mathrm{~m}, 0.5 \mathrm{~m}$, and $0.75 \mathrm{~m}$, which simulated diameter to spacing ratios equal to $10 \%, 20 \%$, and $30 \%$, respectively using a $2.5 \mathrm{~m}$ center to center spacing. It is evident that the factors of safety for the two aforementioned methods and for the short-term condition were increased when using larger sizes of stone columns.
Table 1. Properties of embankment, soft soil and stone column for a $0.5 \mathrm{~m}$ column diameter and a $2.5 \mathrm{~m}$ center to center spacing for short-term condition.

\begin{tabular}{|c|c|c|c|c|}
\hline Item & $\begin{array}{c}\text { Height } \\
(\mathrm{m})\end{array}$ & $\begin{array}{c}\text { Cohesion } \\
(\mathrm{kPa})\end{array}$ & $\begin{array}{c}\text { Friction } \\
\text { angle } \\
(\text { Deg. })\end{array}$ & $\begin{array}{c}\text { Unit } \\
\text { weight } \\
\left(\mathrm{kN} / \mathrm{m}^{3}\right)\end{array}$ \\
\hline Embankment & 5 & 0 & 32 & 18 \\
\hline Clay & 10 & 20 & 0 & 16 \\
\hline Sand & 2 & 0 & 30 & 18 \\
\hline Column & 10 & 0 & 38 & 17 \\
\hline
\end{tabular}

Table 2. Properties of embankment, soft soil and stone column for a $0.5 \mathrm{~m}$ column diameter and a $2.5 \mathrm{~m}$ center to center spacing for long-term condition.

\begin{tabular}{|c|c|c|c|c|}
\hline Item & $\begin{array}{c}\text { Height } \\
(\mathrm{m})\end{array}$ & $\begin{array}{c}\text { Cohesion } \\
(\mathrm{kPa})\end{array}$ & $\begin{array}{c}\text { Friction } \\
\text { angle } \\
(\text { Deg. })\end{array}$ & $\begin{array}{c}\text { Unit } \\
\text { weight } \\
\left(\mathrm{kN} / \mathrm{m}^{3}\right)\end{array}$ \\
\hline Embankment & 5 & 0 & 32 & 18 \\
\hline Clay & 10 & 5 & 25 & 16 \\
\hline Sand & 2 & 0 & 30 & 18 \\
\hline Column & 10 & 0 & 38 & 17 \\
\hline
\end{tabular}

In short-term condition, the factor of safety values calculated from the equivalent improved ground method were greater than those computed from the column wall method. This may be attributed to the fact that the equivalent improved ground method provides continuous failure surface in such a way that every point located on that slip surface reached its shear strength at the same time unlike the column wall method where no continuous slip surface was observed and not all the points mobilized their shear strengths [14]. While, the computed factors of safety for both methods were identical for long-term condition. This is consistent with reference [14] findings in long-term condition since all failure points located on the slip surface have mobilized their shear strengths at the same time. For long-term condition, the effect of increasing the column diameter had no influence on the factor of safety values since the effective cohesion and effective friction angle of soft clay were introduced in long-term case so that the slip surface would not enter the strengthened ground zone. In addition, short-term condition yielded lower factors of safety than long-term condition.

\subsection{Spacing between stone columns}

The impact of the center to center spacing on the factor of safety in both short-term and long term is depicted in Figure 5. The chosen values of center to center spacing were varied from $1.67 \mathrm{~m}$ to $5 \mathrm{~m}$ to match diameter to spacing ratios from $30 \%$ to $10 \%$ [1]. A $0.5 \mathrm{~m}$ column diameter was used for all models. The factors of safety were found to decrease with the increase in stone column spacing for the two methods in short-term condition. As discussed earlier, higher values of factor of safety were 
obtained from the equivalent improved ground method compared with the column wall method in short-term condition. Whereas for long-term condition, the effect of column spacing was insignificant because the stability failure is dependent on the embankment material properties rather than the improved ground properties.

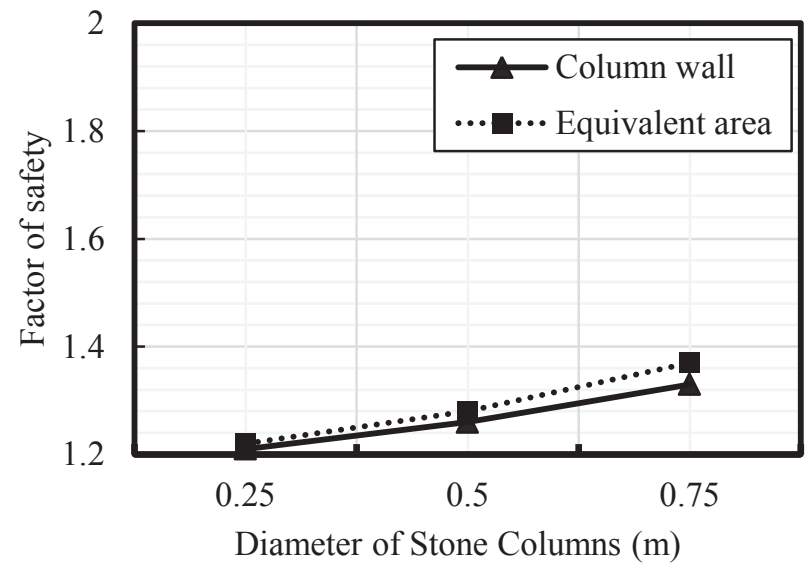

(a)

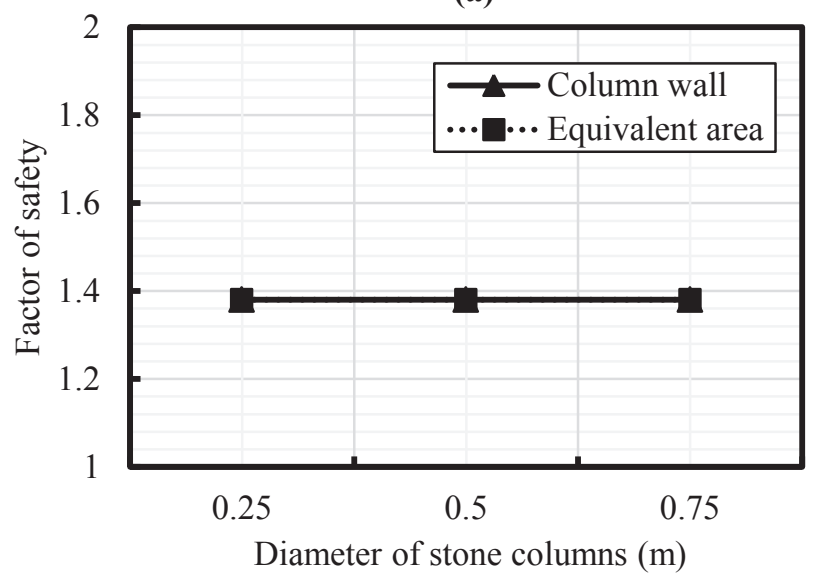

(b)

Fig. 4. Influence of the stone column diameter: (a) short-term condition; and (b) long-term condition.

\subsection{Cohesion of soft soil}

Figure 6 depicts the effect of soft soil cohesion on the factor of safety for both column wall and equivalent improved ground methods in short-term condition only (i.e. undrained cohesion). It is evident that the factor of safety is significantly increased once the soil cohesion changes in a range from 10 to $25 \mathrm{kPa}$. However, the effect of increasing the cohesion greater than $25 \mathrm{kPa}$ has a minimal influence on the computed factor of safety by the two methods because the strengthened soft clay soil was able to prevent the slip surface from developing within the foundation area and to generate within the embankment zone instead. Also, the factors of safety obtained from equivalent improved ground method were greater than those resulted from column wall method because of the continuous slip surface developed in equivalent area method.

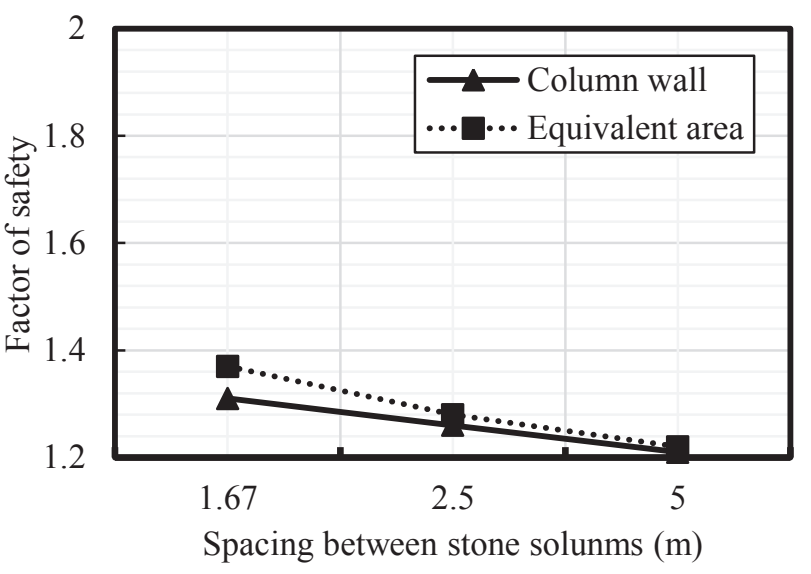

(a)

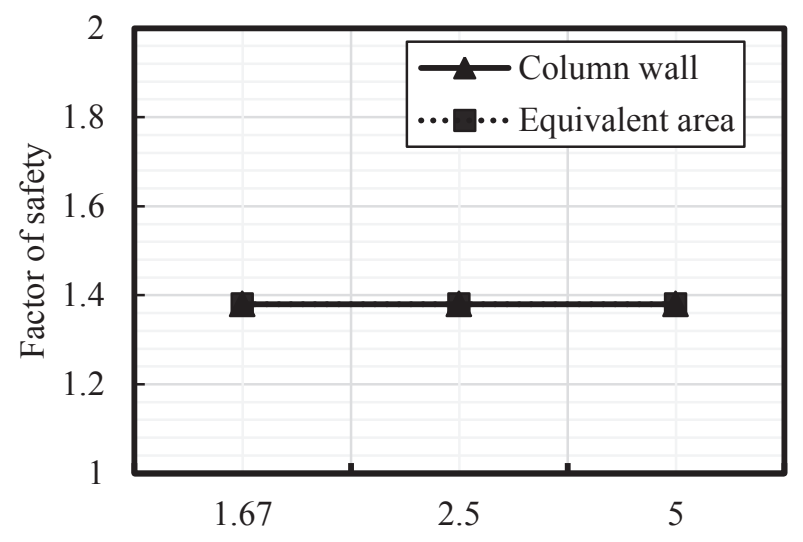

Spacing between stone colunms (m)

(b)

Fig. 5. Influence of center to center spacing between granular columns: (a) short-term condition; and (b) long-term condition.

\subsection{Friction angle of soft soil}

Figure 7 illustrates the factor of safety against the angle of internal friction of the soft clay soil in long-term condition while keeping the effective cohesion equal to $5 \mathrm{kPa}$ for all cases. There is an increase in the factor of safety with the increase of the friction angle of soft soil for both column wall and equivalent improved ground methods. While, increasing the friction angle beyond a $20^{\circ}$ had an insignificant effect since the strengthened foundation ground had prevented the slip surface from penetrating throughout the composite ground. In other words, the failure surface was influenced by the embankment properties only. The computed factors of safety using column wall method and the equivalent improved ground method were identical in long-term condition as mentioned earlier. 


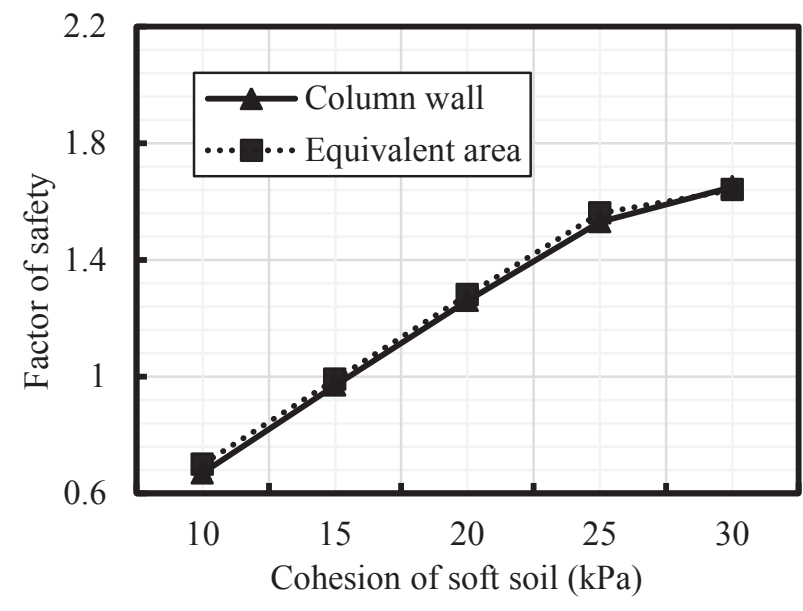

Fig. 6. Effect of soft soil cohesion for the short-term condition.

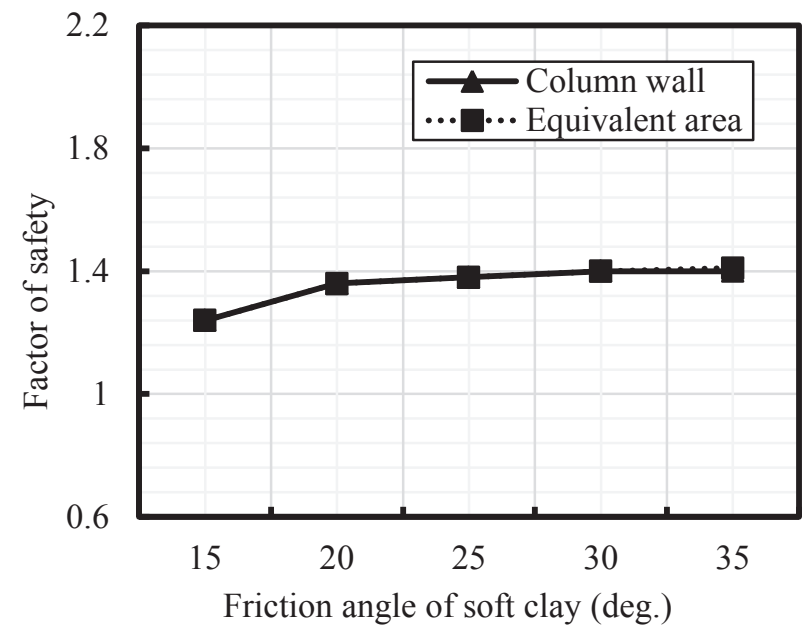

Fig. 7. Effect of friction angle of soft soil for the long-term condition.

\subsection{Height of fill embankment}

Figure 8 shows the effect of embankment height on the embankment stability for both short-term and long-term conditions represented by column wall and equivalent improved ground methods. It is obvious that increasing the height of embankment from $2 \mathrm{~m}$ to $8 \mathrm{~m}$ resulted in a remarkable decrease in the values of factor of safety for both short-term and long-term conditions. Equivalent improved ground method generated slightly higher values of factor of safety than the column wall method in shortterm condition. Similarly, the factors of safety computed from aforementioned methods were identical in long-term condition.

\subsection{Friction angle of fill embankment}

In this study, the material of embankment was modeled as a cohesionless material. Figure 9 depicts the effect of the friction angle of the embankment on the stability factor of safety using the column wall method and the equivalent improved ground method in short-term and long-term conditions. In the short-term, the influence of improving the quality of embankment fill (i.e. increasing the friction angle) had an insignificant effect on the embankment stability if the friction angle increased above $30^{\circ}$. This finding is supported by reference [1] who concluded that increasing the friction angle of the embankment material beyond $30^{\circ}$ had no influence on the stability factor of safety. This may be associated to that the potential slip surface penetrated deeper throughout the composite foundation and highly influenced by the foundation contribution rather than the embankment material properties. Whereas in long-term condition, there was a continuous increase in the factor of safety values as the angle of the internal friction of the embankment increased.

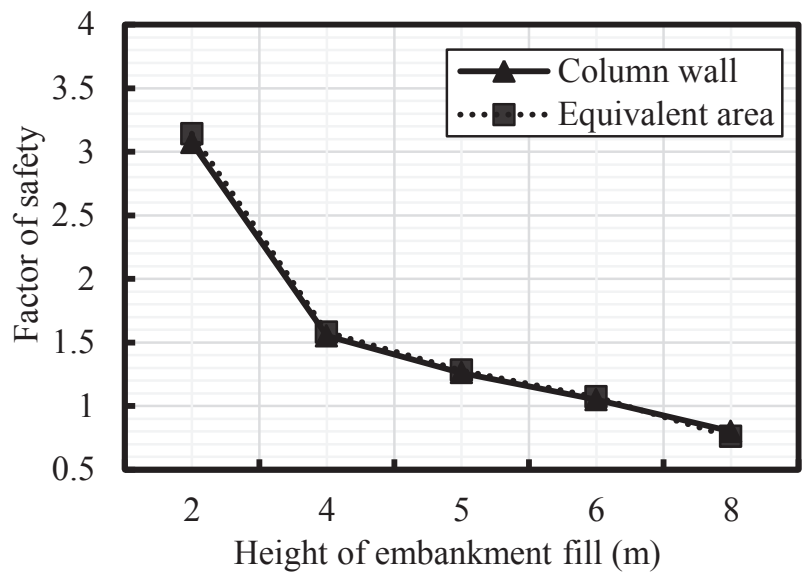

(a)

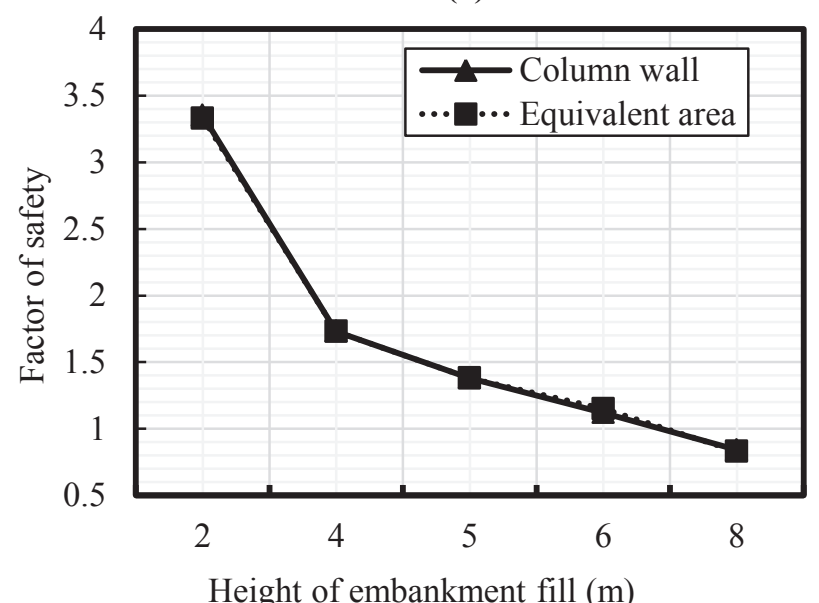

(b)

Fig. 8. Effect of embankment height: (a) short-term condition; and (b) long-term condition. 


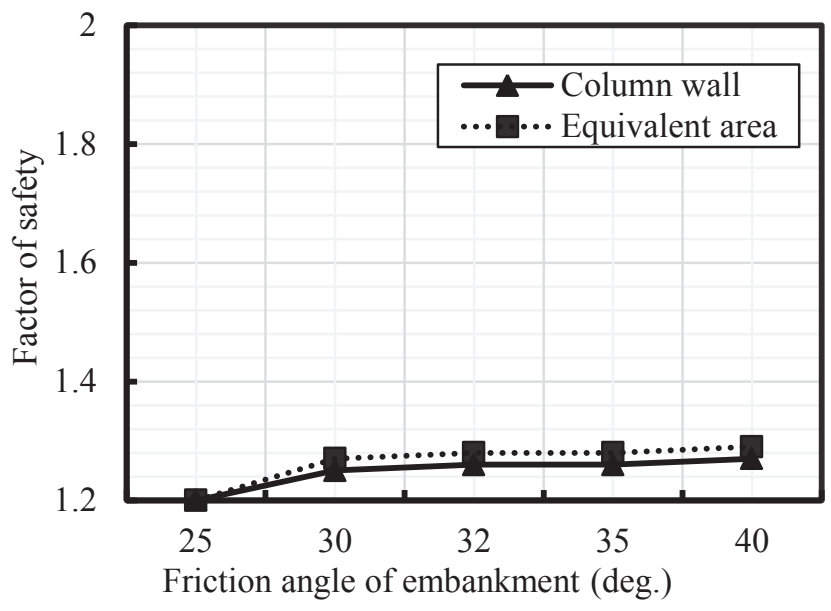

(a)

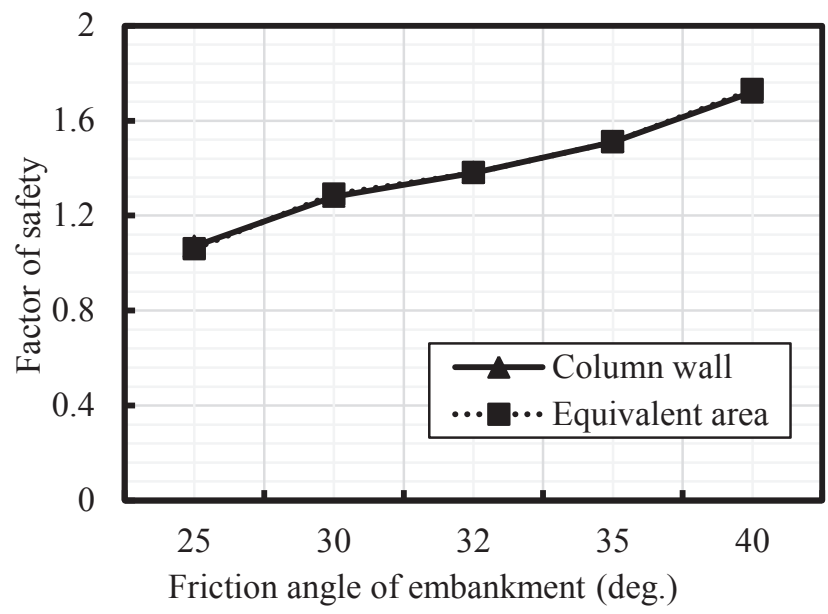

(b)

Fig. 9. Effect of the embankment friction angle: (a) short-term condition; and (b) long-term condition.

\section{Conclusions}

In order to assess the factor of safety against general deepseated failure for embankments constructed on granular column-improved ground with the presence of water table, a two-dimensional finite difference numerical analysis was performed using FLAC/SLOPE 7.0 software. A parametric study was conducted in short-term and long-term conditions. Some conclusions might be drawn from this research:

1. The stability of stone column-supported embankments was investigated in short-term and long-term conditions. The results of the numerical analysis showed that the stability factors of safety of the embankment in short-term condition were less than those computed in long-term condition since the short-term condition is considered the worst case scenario in the field.

2. The factors of safety obtained from equivalent improved ground method were found to be higher than those from the column wall method in short-term condition because of the continuous failure surface that was developed in the equivalent improved ground method as compared with the column wall method.

3. The stability factors of safety of embankments constructed on the stone column-improved ground were identical when using column wall and equivalent improved ground methods in long-term condition. This is mainly attributed to that all the points located on the potential slip surface have reached their shear strengths at the same time. 4. A considerable decrease in the stability factors of safety occurred after increasing the spacing measured from center to center between ordinary stone columns. While the embankment stability was improved when using stone columns of larger diameters for short-term condition.

5 . The factor of safety considerably increased when the cohesion of the soft soil was less than $25 \mathrm{kPa}$ for shortterm condition and when the angle of the internal friction of the soft soil was less than $20^{\circ}$ for long-term condition because the slip surface could not penetrate the strong composite ground.

6. Increasing the height of the embankment caused a significant decrease in the stability factor of safety for both short-term and long-term conditions.

7. No remarkable effect on the factor of safety was noticed when increasing the friction angle of the embankment beyond $30^{\circ}$ in short-term condition. For long-term condition, improving the quality of embankment fill (i.e. using a material with the higher angle of the internal friction) had a substantial role in the stability of stone column-supported embankment.

\section{References}

1. S. Abusharar, J. Han, Eng. Geo., 120, 103-110, (2011) 2. A. P. Ambily, S. R. Gandhi, ASCE J. Geotech. Geoenviron. Eng., 133, 405-415, (2007)

3. M. Cala, J. Flisiak, FLAC and Numerical Modeling in Geomechanics, Ecully-Lyon, France, (2001)

4. Y.M. Cheng, C.K. Lau, Slope Stability Analysis and Stabilization: New Methods and Insight, Routledge, UK, (2008)

5. J. Han, S. L. Ye, $1^{\text {st }}$ Young Asian Geotechnical Engineers Conference, Thailand, 197-206, (1991)

6. J. Han, R. L. Parsons, A.R. Sheth, J. Huang, Deep Mixing Conference, Sweden, 1.2, 231-236, (2005)

7. J. Han, D. Leshchinsky, $8^{\text {th }}$ Int. Geosynthetics Conference, 1347-1350, Yokohama, Japan, (2006)

8. J. Han, Ground Improvement and Ground Control, 1, 99-113, (2012)

9. ITASCA, FLAC/SLOPE User's Guide Version 6.0, Itasca Consulting Group, Inc., License, (2008)

10. S. Kadhim, R. L. Parsons, J. Han, IFCEE, 2318-2327, (2015)

11. S. R. Lo, R. Zhang, J. Mak, Geotext. Geomembr., 28, 292-302, (2010)

12. D. Mc Kelvey, V. Sivakumar, A. Bell, J. Graham, Geotech. Eng., 157, 137-149, (2004) 
13. S.A. Tan, S. Tjahyono, K.K. Oo, Geotech.

Geoenviron. Eng., 134, 185-194, (2008)

14. Z. Zhang, J. Han, G. Ye, Eng. Geology, 168, 104-113, (2014) 